IAC-03-V.5.01

\title{
NASA'S NEXT GENERATION LAUNCH TECHNOLOGY PROGRAM - STRATEGY AND PLANS -
}

\author{
Uwe Hueter \\ NGLT, Assistant Manager for Strategy \& Plans \\ Uwe.Hueter-1@nasa.gov \\ NASA - Marshall Space Flight Center \\ Marshall Space Flight Center, AL 35812
}

\begin{abstract}
$\underline{\text { Abstract }}$
The National Aeronautics and Space Administration established a new program office, Next Generation Launch Technology (NGLT) Program Office, last year to pursue technologies for future space launch systems. NGLT will fund research in key technology areas such as propulsion, launch vehicles, operations and system analyses. NGLT is part of NASA's Integrated Space Technology Plan. The NGLT Program is sponsored by NASA's Office of Aerospace Technology and is part of the Space Launch Initiative theme that includes both NGLT and Orbital Space Plane. NGLT will focus on technology development to increase safety and reliability and reduce overall costs associated with building, flying and maintaining the nation's next-generations of space launch vehicles. These investments will be guided by systems engineering and analysis with a focus on the needs of National customers.
\end{abstract}

This paper describes the NGLT Program Office's strategy and plans. Current activities, accomplishments, future plans and technologies are discussed.

\section{Introduction}

The National Aeronautics and Space Administration (NASA) established a new program office, Next Generation Launch Technology (NGLT) Program Office, last year to pursue both mid-term and long-term technologies for future space launch systems. NGLT will fund research in key technology areas such as propulsion, launch vehicles, operations and system analyses. NGLT is part of NASA's Integrated Space Technology Plan (ISTP), see Figure 1 which consists of the following three major programs:

- Space Shuttle - To extend the operational life through system-wide investments

- Orbital Space Plane (OSP) - Develop as early as possible a crew transfer, rescue and return capability for the International Space Station

- Next Generation Launch Technology (NGLT) - Develops technology that will enable future launch systems 


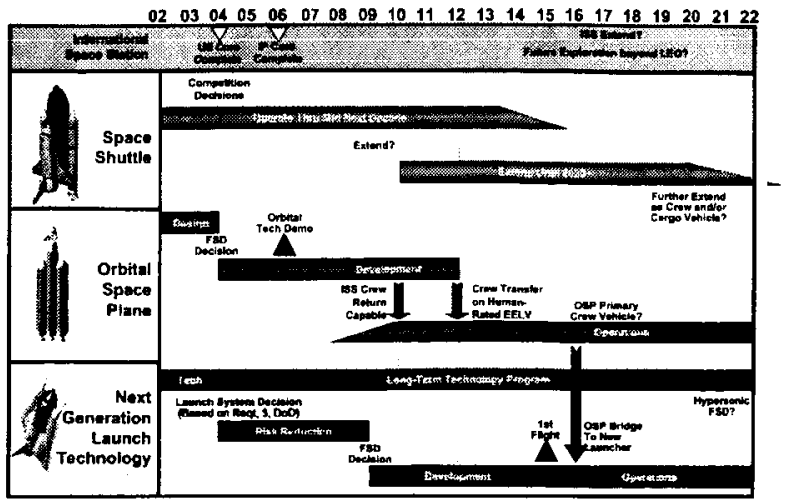

Figure 1. ISTP Roadmap

The NGLT Program is sponsored by NASA's Office of Aerospace Technology (OAT) and is part of the Space Launch Initiative (SLI) theme that includes both NGLT and OSP. NGLT will focus on technology development to increase safety and reliability and reduce overall costs associated with building, flying and maintaining the nation's next-generations of space launch vehicles. These investments will be guided by systems engineering and analysis with a focus on the needs of National customers.

The following sections describe the NGLT program, how it ties into the Department of Defense (DoD) National Aerospace Initiative (NAI), the system engineering and analyses process being used to evaluate technologies, and the technology portfolio.

\section{NGLT Program Overview}

The NGLT Program was established approximately a year ago. The NGLT Program combines the technology programs of both the previous Space Launch Initiative Program $\left(2^{\text {nd }}\right.$ generation launch technology) and the Advanced Space Transportation Program ( $3^{\text {rd }}$ generation launch technology). The NGLT Program is investing in cutting-edge technologies required for future U.S. launch systems and is now the only NASA program that is pursuing both near-term, mid-term, and far-term launch technologies. A major emphasis will be placed on reusable vehicle and propulsion system technologies. Propulsion system technologies for both rocket and airbreathing hypersonic propulsion concepts are being pursued. Although a technology program, NGLT will be guided by solid system analysis and executed using sound management and system engineering principles. Therefore, the NGLT Program Office was structured to focus on these major areas of emphasis, see Figure 2. The investments in technologies are timephased over multiple phases to deliver required technologies to support future National launch system decisions for both NASA and DoD.

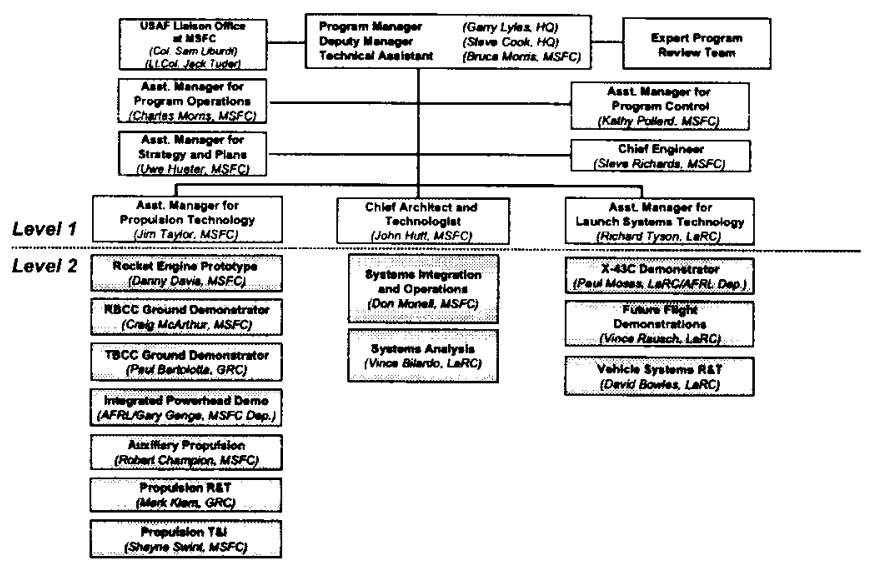

Figure 2. NGLT Organization

The DoD has championed a new national activity named, "National Aerospace Initiative (NAI)." NAI is a partnership between the DoD and NASA whose vision is, "Ensure America's leadership in aerospace." NAI focuses on three major areas (referred to as "Pillars"). The three pillars are Space Access, High Speed Hypersonics, and Space Technology. The objectives of the three pillars are as follows:

- Space Access: Develop and demonstratc technologies that enable responsive, safe, 
reliable, and affordable access to and from space.

- High Speed/Hypersonics: Develop and demonstrate technologies that enable airbreathing hypersonic flight.

- Space Technology: Develop and demonstrate technologies that enable transformational and responsive in-space capabilities.

NGLT is fully integrated and partnering with DoD under the NAI and supports both the High Speed Hypersonics and Space Access Pillar, see Figure 3.

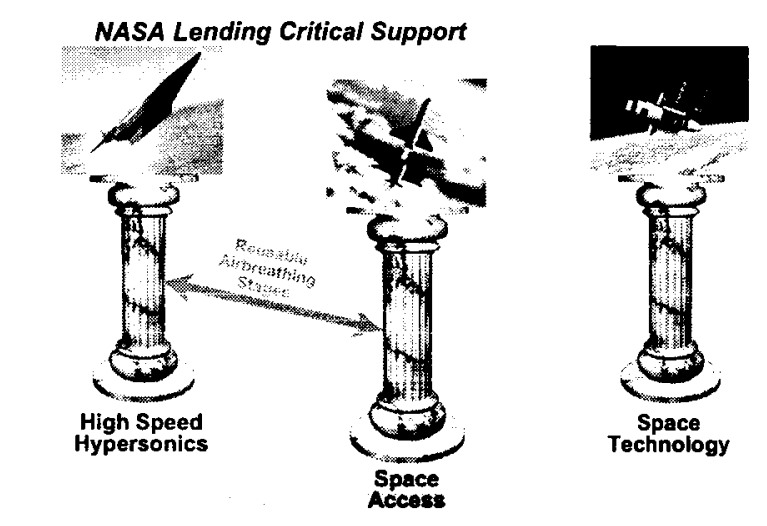

Twenty-five Year National Technology Plan to Mature Key Technologies for NASA and Department of Defense Needs

Figure 3. Three Major NAI Pillars

The NAI Executive Office has been established to manage the activities. The office is located in the Washington, D.C. area and staffed by approximately ten people, see Figure 4. The office was formed around the three major activities (pillars). Its primary function is as a centralized office to provide program advocacy, oversight, strategic planning and coordination among the various stakeholders. Both NASA and DoD staff the office. The execution of the technology projects will take

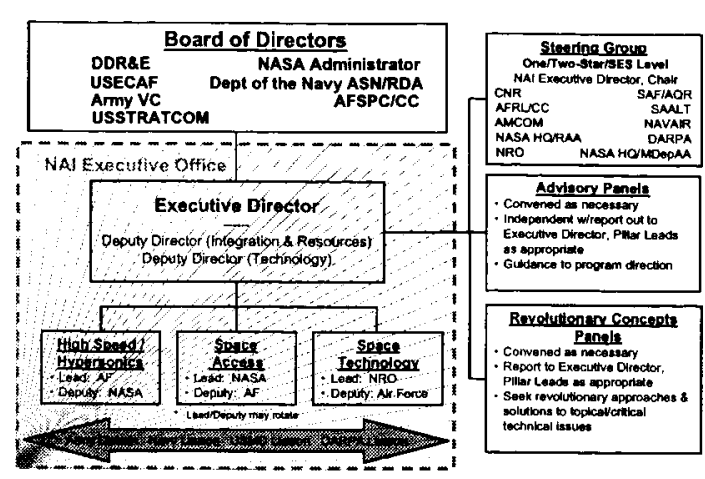

Figure 4. NAI Executive Office

place at the various facilities, both NASA and DoD, throughout the USA.

\section{System Engineering \& Analyses Process}

The objectives of the NGLT System Engineering and Integration activities are as follows:

- Integrate DoD, exploration, science and other launch system customer needs into Level I formulation phase requirements

- Recommend technology development strategies

- Define and maintain architectures and concepts

- Develop project technology development requirements and priorities

- Develop integrated set of lower level technology roadmaps from the ISTP roadmap

- Provide bottoms up assessment of progress towards top level requirements

- Provide credible cost/benefit analyses to support roadmap decisions 
- Provide sensitivity and uncertainty analyses

- Improve systems engineering, integration and analysis capability

The deliverables expected from these activities are launch system scenarios (architectures), mission needs statements, design reference missions, requirements for system to component level, technology development requirements and metrics, roadmaps, costs, and technology investment recommendations. These deliverables will be based on bottoms up assessments, trade analysis, and cost/benefit analyses. The technology planning process flow is shown in Figures 5.

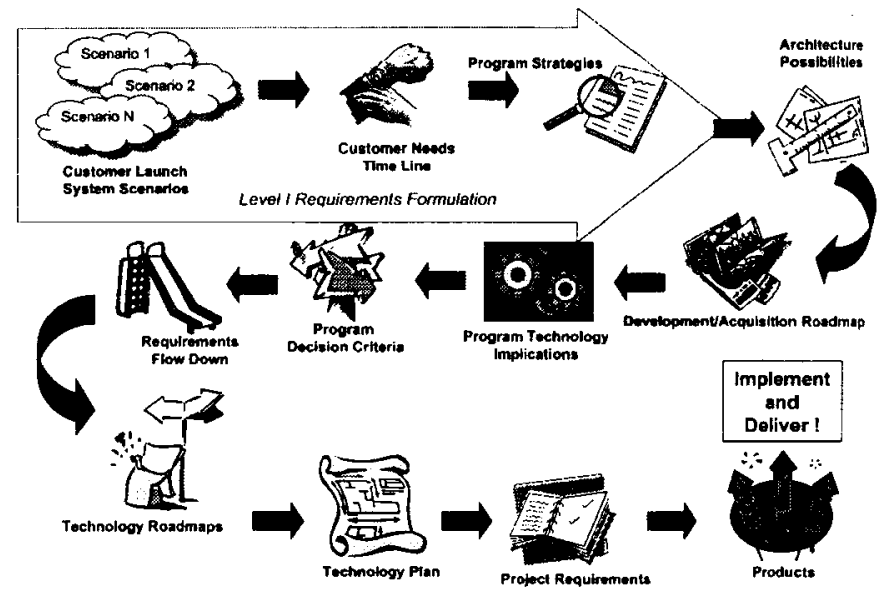

Figure 5. Technology Plan Flow

The step-by-step process used by system engineering and integration to get from mission needs to technology assessment is shown in Figure 6.

Embedded in the process is the System Analysis Project that defines the architectures, performs life-cycle systems and technology assessment, and generally provides the analytical support. The activity will analyze the requirements based on near-term (2010), midterm (2015) and far-term (2020) technology requirements. Some of the potential architectures bcing considered are shown in Figure 7.

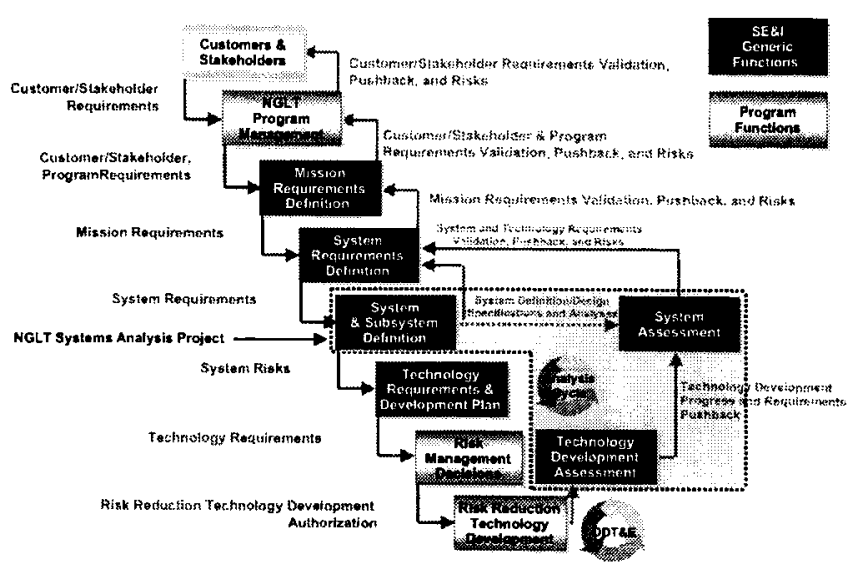

Figure 6. System Engineering and Integration Process Flow

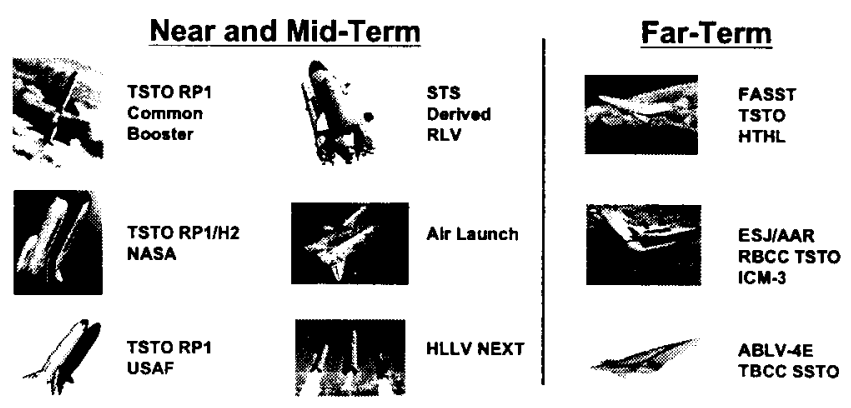

Figure 7. Potential Architectures

\section{Technology Portfolio}

The technologies that the NGLT Program is investing in can be divided into three major areas of emphasis, propulsion, launch systems (vehicle related technologies), and system analyses and engineering (see Figure 2). The latter one has is discussed in the previous section. The emphasis in this section will be on the hardware technologies, propulsion and launch systems.

Propulsion Technology: The NGLT program has seven propulsion technology projects. They include both pure rocket or airbreathing 
propulsion technologies as well as combined systems. Each projects' objectives are briefly described in the following paragraphs.

\section{Rocket Engine Prototype Project:}

This project is focusing on a 1+ MLbs

LOX/Hydrocarbon booster engine. The objectives are to provide risk mitigation for large class, oxygen rich stage combustion engines; design and test a high-fidelity prototype engine that supports NASA's increased safety and reliability goals and reduced operations and cost goals; validate existing analytical tools needed to support prototype engine development by subscale and full scale testing; and develop and validate new analytical tools as required to develop the flight engine system.

\section{Rocket Based Combined Cycle (RBCC) Project: This project is} focusing on a rocket-based airbreathing engines for ground testing from Mach 0 to 7 . The objectives are to validate predictive capabilities; demonstrate limited flight-like engine system design and fabrication techniques; evaluate engine system operational characteristics; and provide a testbed for evaluation of candidate innovative components.

\section{Turbine Based Combined Cycle} (TBCC) Project: This project is focusing on a turbine based airbreathing engines for ground testing up to Mach $4+$. The objectives are to advance current state-of-the-art turbine engine technologies such that a TBCC propulsion system can be a viable propulsion system to meet space access goals for cost \& safety; provide testbed for evaluation of candidate innovative technologies; validate predictive capabilities including propulsion and vehicle system analysis models; and evaluate engine system operational characteristics.

Integrated Powerhead Demonstration (IPD): The project is currently testing a $250 \mathrm{Klb}$ thrust oxygen/hydrogen full flow stage combustion engine. The objectives are to demonstrate feasibility and benefits of a full flow cycle; provide key component technology validation for long life rocket engine using oxygen / hydrogen engine components and oxygen rich gas path components; and provide validation of tools being used.

Auxiliary Propulsion Systems: The project objectives are to develop auxiliary propulsion technologies, reduce development risk for future launch systems; demonstrate significantly improved auxiliary propulsion system safety, operability, and reliability while reducing costs; demonstrate operation of dual thrust reaction control systems with safe, operable non-toxic propellants; expand the knowledge base in H202/JP-8 through component development and propellant characterization; develop cryogenic fluid management technologies; and develop and test prototype auxiliary propulsion hardware.

R\&T Propulsion: The research and technology (R\&T) propulsion projects, Propulsion Research \& Technology (PR\&T) and Propulsion Technology and Integration (PT\&I), conduct the initial technology activities prior to inserting these technologies into a system level environment, e.g., ground or flight demonsirator. A lot of the 
technologies are being focused toward the operational or "vision" vehicle. Material research, component development (including sensors), and analytical tool development are the major areas of interest. The specific areas being invested in by each of the projects are described in the following paragraphs.

The PR\&T Projects main focus is in the following areas:

- Rotating components and seals for use in TBCC high temperature turbine systems, disks and rotors, and ceramic turbine blade.

- Flowpath components for inlets, Ram combustion physics, wide operating range designs, integrated thermal balances, test instrumentation, cooled panels, large static structures, static and sliding seals and air augmented rockets.

- Engineering capabilities, e.g., vehicle life prediction \& health management, systems integration \& design optimization, education program.

The PT\&I Projects main focus is in the following areas:

- Demonstration of vacuum plasma spray processes for forming the main combustion chamber liner at main engine scale.

- Demonstrate miniaturization of sensors capable of withstanding appropriate environment for reusable propulsion system applications for hydrogen, oxygen, and hydrocarbons.

- Validated processes for production of GRCop-84 in both sheet and plate for MCC fabrication.

- Significant risk reduction and validated alternative approaches for high risk RP-1 prototype components.

\section{Launch Systems Technology: The NGLT} launch systems technology project has two major technology areas, Vehicle Systems Research \& Technology (VSR\&T) and Flight Demonstrators. VSR\&T includes both the basic vehicle systems such as airframe structures and materials and thermal protection systems (TPS) as well as the subsystems and range. The flight demonstrators include both planned and future demonstrators. Each projects' objectives are briefly described below.

Vehicle Systems R\&T: The project has five major areas of emphasis (see Figure 8). The focus is on developing all vehicle related technologies not covered by the propulsion projects. Included in these sub-projects are vehicle structural ground demonstrators and small flight experiments. Of the VSR\&T budget approximately $50 \%$ is focused on developing airframe structures and $20 \%$ on subsystem. Most of the technologies are being focused toward the operational or "vision" vehicle. 


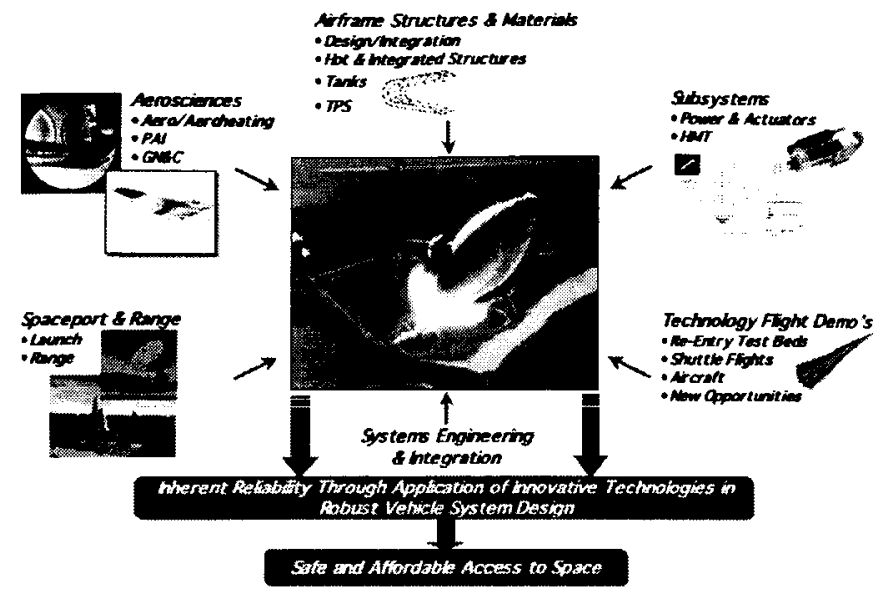

Figure 8. Launch Systems Technology Emphasis

Flight Demonstrators: The project's objectives are to reduce future operational vehicle development risk; demonstrate, validate and advance the technology, experimental techniques, and computational methods and tools for design and performance predictions of air-breathing hypersonic vehicles; flight-validate hypersonic vehicle/propulsion system performance and design methods; validate cost and operational models; and flightdemonstrate selected key vehicle reliability and maintainability technologies. The key flight demonstrators are shown in Figure 9.

The X-43A project consists of three expendable Mach 7 and 10 scramjet flight demonstrator vehicles. First flight of the X-43A, at Mach 7, was attempted on June 2, 2001. The flight was terminated after a booster failure 13.5 seconds into the mission. The second flight at Mach 7 should occur this year and the third flight at Mach 10 is planned for next year.

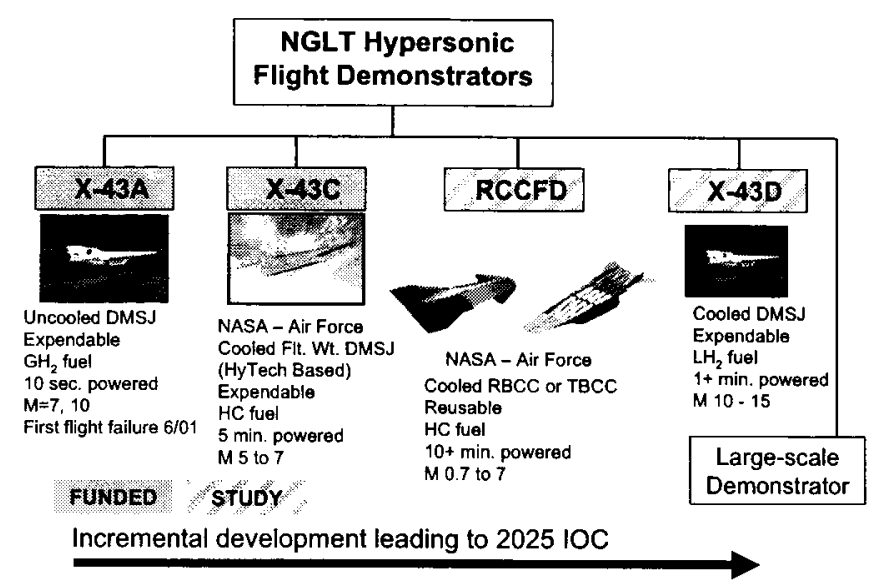

Figure 9. Hypersonics Flight Demonstrators

The vehicles are 12 foot in length and boosted to their test condition by being dropped from a B-52 airplane and boosted by a first stage Pegasus rocket.

The X-43C project's objectives are to demonstrate autonomously controlled, accelerating, free flight of a hydrocarbon-fuel-cooled, dual-mode scramjet powered vehicle from Mach 5 to Mach 7, including combustion mode transition from ramjet to scramjet. The engine for $\mathrm{X}-43 \mathrm{C}$ is based on and provided by the Air Force HyTech Program. This demonstration includes flight performance of hydrocarbon fuelcooled, dual-mode scramjets in steady and maneuvering flight; flight characteristics of air breathing hypersonic vehicles in powered and unpowered flight; ground and flight data to validate computational methods, analytical predictions, and test techniques; and propulsion operability to enable design of future operational vehicles. This is a joint effort between NASA and the United States Air Force (USAF). The project consists of three 
flights, each flight will explore a portion of the flight envelop for specific propulsion issues and aero-propulsive interactions. The first flight is planned for $2007 / 2008$.

The Reusable Combined Cycle Flight Demonstrator (RCCFD) is currently being studied to establish the requirements, design, and performance. The demonstrator will utilize a hydrocarbon fuel-cooled combined/combination cycle propulsion system, either RBCC or TBCC. The RCCFD will be air launched and then self-powered to accelerate from Mach 0.7 to 7 to demonstrate all propulsion modes from subsonic flight through full scramjet operation. Preliminary studies have indicated the vehicle will be approximately 35 to 45 feet in length. This will be the first fully reusable hypersonic demonstrator, allowing many more flights to explore the operational envelope, extended flight duration, and prove system durability.

X-43D Mach 15 hydrogen fueled demonstrator will demonstrate hypervelocity scramjet engine technology development. This is a required risk reduction, before proceeding with a near full-scale demonstrator vehicle. The X-43D flight demonstration vehicle is envisioned to fill that need. The X-43D is in a formulation stage, but some elements of the vehicle requirements are evolving. The first major requirement is a scramjet engine capable of performing (accelerating) at Mach 15 with hydrogen fuel. To keep vehicle size reasonable and project costs down, the demonstration would likely be a short duration ( 30 seconds to several minutes at most) flight from an initial velocity of
Mach 15. Packaging liquid hydrogen fuel for a 30 seconds flight will drive the vehicle length to about 24 feet. Boosting this size vehicle will require a 2-stage Peacekeeper class booster. The first of several flights is planned for approximately 2012 .

The Large-Scale Reusable Demonstrator (LSRD) vehicle is currently envisioned as being the same architecture (SSTO or TSTO, VTHL or HTHL) as the 2025 operational vehicle, and sized capable of operation over all air-breathing propulsion speeds. In addition, if a SSTO concept is selected, the vehicle may include the final rocket mode plus sufficient propellant to execute mode transition to rocket. Selection of the vehicle concept will be made about 2010 , and first flight is estimated to be around 2017. This will be the first demonstrator to fully integrate both propulsion and airframe technologies in a reusable flight demonstrator.

The integrated time-phased plan of the technologies and how they are infused into future demonstrators is depicted in the roadmap shown in Figure 10. There are multiple decision points along the path leading to an operational vehicle decision where technologies can be incorporated into either ground or flight demonstrators or spun off to other acquisition programs. This approach allows for the development of spiral operational capability. Annual reviews will provide the opportunity of redirecting the technology priorities to adjust for any shortfalls in the technology portfolio or in the maturation of the baseline technologies. 


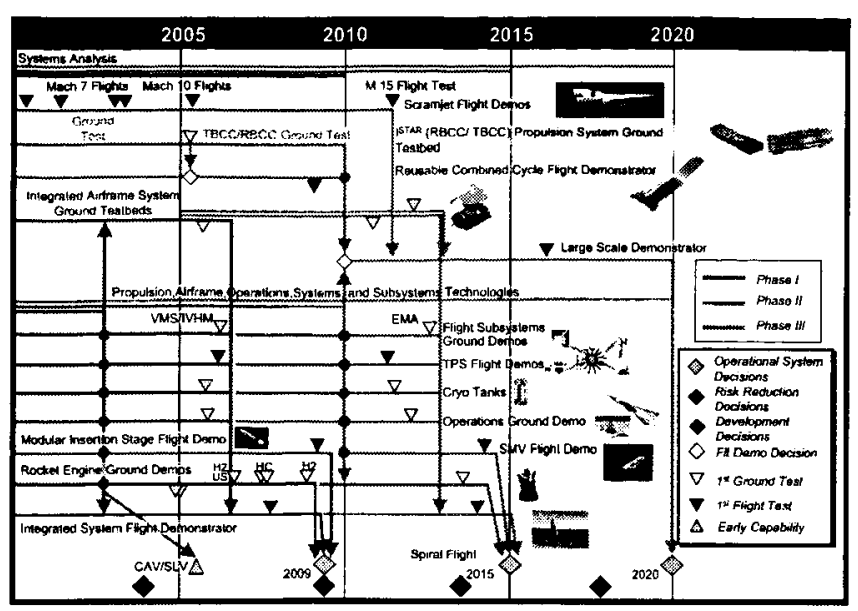

Figure 10. Technology Roadmap

Based on the above description of the technology portfolio, many products in various technology disciplines will be produced over the course of the program. These products will be required for the development of next generation launch systems. The NGLT program products are summarized in Figure 11.

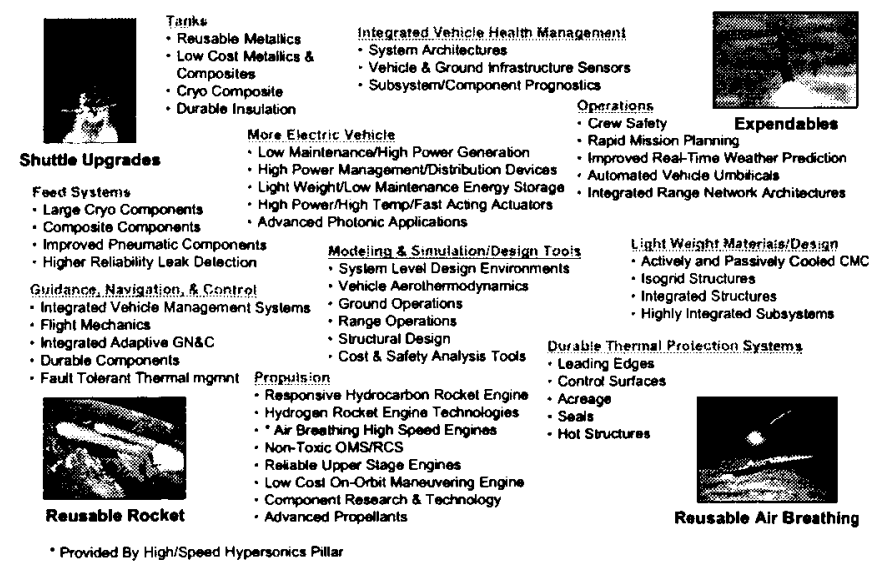

Figure 11. Technology Product Summary

\section{$\underline{\text { Summary }}$}

The NGLT Program is investing in cuttingedge technologies required for future U.S. launch systems. The investments will be guided by system analysis and executed using sound management and system engineering principles. The investments in technologies are time-phased to deliver required technologies to support upcoming National launch system decisions. NGLT is fully integrated and partnering with DoD. An integrated timephased plan of the technologies allows for multiple decision points along the path. Technologies are incorporated into ground and/or flight demonstrators that can be spun off to other acquisition programs. This approach allows for the development of spiral operational capability. Annual reviews will allow the opportunity of redirecting the technology priorities to adjust for any shortfalls in the technology portfolio or in the maturation of the baseline technologies. 